Narrative Works

Issues, Investigations, \& Interventions

\title{
Ethnopoetics and Narrative Analysis
}

\section{Paul Atkinson and Natasha Carver}

Volume 10, 2020

Special Issue: Amor Narratio: A Festschrift For Catherine Kohler Riessman

URI: https://id.erudit.org/iderudit/1076918ar

DOI: https://doi.org/10.7202/1076918ar

See table of contents

Publisher(s)

Centre for Interdisciplinary Research on Narrative, St. Thomas University

ISSN

1925-0622 (digital)

Explore this journal

Cite this article

Atkinson, P. \& Carver, N. (2020). Ethnopoetics and Narrative Analysis. Narrative Works, 10, 60-70. https://doi.org/10.7202/1076918ar

\section{Article abstract}

We acknowledge and concur with Catherine Kohler Riessman's insistence on the necessity of sustained and formal analysis of narratives. We thus distance ourselves from qualitative researchers who aim to celebrate personal narratives rather than undertaking that analytic work. In doing so, we also draw on the work of Dell Hymes, whose approach to ethnopoetics informs our own. The discussion is developed and illustrated with materials from Natasha Carver's research with informants of Somali heritage that display the relevance of ethnopoetic transcription and analysis.
This document is protected by copyright law. Use of the services of Érudit (including reproduction) is subject to its terms and conditions, which can be viewed online.

https://apropos.erudit.org/en/users/policy-on-use/ 


\title{
) ( $)$ NARRATIVE WORKS
}

\author{
SPECIAL ISSUE \\ AMOR NARRATIO: A FESTSCHRIFT FOR \\ CATHERINE KOHLER RIESSMAN
}

\section{Ethnopoetics and Narrative Analysis}

\author{
Natasha Carver \& Paul Atkinson \\ University of Bristol Cardiff University
}

\begin{abstract}
We acknowledge and concur with Catherine Kohler Riessman's insistence on the necessity of sustained and formal analysis of narratives. We thus distance ourselves from qualitative researchers who aim to celebrate personal narratives rather than undertaking that analytic work. In doing so, we also draw on the work of Dell Hymes, whose approach to ethnopoetics informs our own. The discussion is developed and illustrated with materials from Natasha Carver's research with informants of Somali heritage that display the relevance of ethnopoetic transcription and analysis.
\end{abstract}

\section{Keywords:}

Ethnopoetics, representation, Riessman, narrative analysis, reflexivity

Catherine Kohler Riessman's work on narrative insists on formal analysis: narratives are spoken performances that demand close reading for their organizational properties. Such a perspective goes beyond the Romantic celebration of narrative as the expression of personal experiences and emotions, recognizing that even the most personal things are expressed through culturally shared resources, including discursive conventions (see Atkinson \& Silverman, 1997; Plummer, 1995). Riessman $(1993,2008)$ provided a thorough critique of the limitations of narrative analysis as a method as well as scholarly guidance on its opportunities and benefits. She observed that the most common mode of narrative analysis was content-based or thematic, in which "language is used as a resource rather than a topic of inquiry" (2008, p. 59). This approach, she observed, fails to address the organizational and dialogic features of language, and hence sells short the analytic possibilities 
presented by narrative materials. In such texts, chunks of interview response are often reproduced with little or no account of their discursive context or of how they are embedded within narrative structures. The structural model offered by Labov (2013), on the other hand, while addressing narrative organization, limited the definition of a narrative to "a discrete unit of discourse, an extended answer by a research participant to a single question," which was "topically centred and temporally organised" (Riessman 2008, p. 5). In addition, Riessman found that Labov's focus on the function of clauses in narrative storytelling did not take sufficient account of the prosodic features of speech.

Following Riessman, we here invoke the analytic perspective of ethnopoetics first proposed by Hymes (e.g., 1996), who observed how the reproduction of orally-recounted folktales in prose form obliterated not just the performative dimensions, but also the intrinsic structure and linguistic properties of these accounts. He used his knowledge of the genres and his poetic competence to derive transcription strategies that reflected the poetic structures of those spoken activities. Such reconstruction was a restitutive act, returning to indigenous speakers their cultural heritage and rendering its tacit skills visible (Blommaert, 2006b). For Hymes, narratives are "connected by a 'grammar' of narration" of which the speaker may be only partially aware (as cited in Blommaert, 2006a, p. 260), and ethnopoetics was thus a "method of revealing culturally specific relations of form and meaning" (as cited in Blackledge et al., 2016, p. 654). He focused on oral cultures, which he saw as linguistically and socially disadvantaged. Although rightly criticized for essentializing culture, the emancipatory possibilities of Hymesian ethnopoetics make it a method worth rescuing (Blackledge et al., 2016). As Riessman (1993) puts it, "Western, white, middle-class interviewers seem to expect temporally sequenced plots and have trouble hearing ones that are organized episodically" (p. 17). In educational settings in the U.S., Gee (2014, 2015), Mills et al. (2021) and Riessman (2008) have all observed how privileging certain forms of (White, middle-class) storytelling further disadvantages Black American children whose stories frequently go unheard or are dismissed as "bad." Blommaert (2006a) and Blackledge et al. (2016), meanwhile, have demonstrated how an ethnopoetic approach can be applied to a variety of settings in which narratives are produced cross-culturally and may be of particular import in professional settings marked by inequality.

Riessman's recourse to ethnopoetics stemmed from her desire for rigorous and accountable analysis. In Divorce Talk (1990), her 
participants were White North Americans, well versed in both the social codes that accompany (North American) English-language conversation (Heritage \& Clayman, 2010) and in the interview as a site of selfformation and display (Atkinson \& Silverman 1997). Riessman (1990, p. 79) wanted a method to analyze not just content and themes, but also structure and form, and the dialogical and performative aspects of narrative. Ethnopoetics uses line and stanza as a means of representing the shared meaning achieved in oral exchanges that are easily lost through the transcription process. In English language conversation, people do not often speak in grammatical, fully-structured, and comprehensive sentences. They do not even speak in clauses (as per Labov, 2013). Rather, they speak in small spurts or idea units - shaped by tone, pitch, rhythm, and pause-clustered together in stanzas (Gee, 2014, 2015; Riessman, 2008). In well-rehearsed narratives, language content and prosodic delivery dovetail. For unrehearsed extended turns, and particularly for those who are grammatically weak, prosody can be more important than language content, providing meaning to otherwise incomprehensible passages and repairing instances of grammatical incoherence (Blackledge et al., 2016; Blommaert, 2006a).

In the second half of this paper, we use material from Carver's (in press) research on marital relations after migration in order to demonstrate how ethnopoetics can aid narrative analysis. Building on the work of Riessman and Gee, alongside Blommaert's development and application of Hymes, we suggest that ethnopoetics can be an eminently useful method for narrative content analysis and has the potential to play a further role, in addition to those already identified by these authors, in relation to reflexivity and (re)presentation.

\section{Content and Themes}

Riessman (1990) demonstrated a "relationship between the 'point' a narrator makes and the form of expression he or she chooses" (p. 117). She showed that the close examination of structure is crucial for a thorough and rigorous analysis of meaning. In the extract below, we explore the relationship between prosodic structure and meaning in a participant's response to a question requesting an account of the best wedding she had been to. Natasha met Bilan during the course of fieldwork, while volunteering for a charity which runs a weekly drop-in. By the time of the recorded interview, they had known each other for 14 months: 
Stanza One

Bilan:

Natasha:

Stanza Two

Bilan:

Natasha:

$\begin{array}{cc}\mathrm{x} / & (.) \\ \text { Because (.) }\end{array}$

the best wedding I have ever been

is the best wedding they do with the culture, the Somali culture, way.

ok.
1

2

$\mathrm{x} / \mathrm{x} / \mathrm{x} / \mathrm{x} / \mathrm{x}$

before when I was in Somalia,

$\mathrm{x} / \mathrm{x} / \mathrm{x} / \mathrm{x} / \mathrm{x} / \mathrm{x}$

I used to love errr European culture.

x / /

The white dre:ss,

x / /

the black sui:t,

$\mathrm{x}$ / /

the musi:c,

/ / $\mathrm{x} /$

When I was young.

yeah.

\section{Stanza Three}

Bilan: $\mathrm{Bu}: \mathrm{t}$

$$
\text { / } \mathrm{x} \text { / } \mathrm{x} \text { / }
$$

when I back I see ( 1 )

$\mathrm{x} \mathrm{x} / \mathrm{x} / \mathrm{x} / \mathrm{x} / \mathrm{x} / \mathrm{x}$

the Soma- the real Somali culture wedding.

$\mathrm{x} / \mathrm{x} / \mathrm{x} / \mathrm{x} /$

The girl wear dress Somali dress,

/ $\mathrm{x} / \mathrm{x}$

( 1 ) especial

$\mathrm{x} / \mathrm{x} / \mathrm{x}$ / $\mathrm{x}$

the man wear too white clothés.

$\mathrm{x} / \mathrm{x} / \mathrm{x}$

They danc:e, without er

$\mathrm{x} / \mathrm{x}$ /

they dance with drum,

all the night and singing,

Stanza Four

A:nd

x / $\mathrm{x}$ x

you know, I don't know,

$\mathrm{x} \times$ / $\mathrm{x} / \mathrm{x} \mathrm{x}$

in a way $I$ love that way.

$\mathrm{x} / \mathrm{x} / \mathrm{x} /$

I don't know maybe my

$\mathrm{x} / \mathrm{x} / \mathrm{x} / \mathrm{xxx} / \mathrm{x}$

I see so many European wedding,

Natasha:

yeah. 
Bilan:

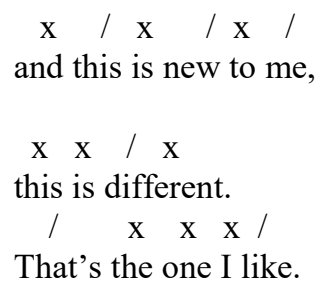

One of the simplest rhetorical devices, employed by everyday speakers and great orators alike, is the list of three, seen here in lines 7, 8 and 9. This could be easily recognized and picked out for analysis in any format, even if the quote were written in prose. By using ethnopoetics, however, we can see that this list of three is in fact part of a stanza with a very distinctive and sophisticated scansion. Indeed, the rhythm is so important to Bilan that she emphasizes both syllables in "music" in order to maintain the pattern. Further, all three in the list end with lengthened vowel sound and well-articulated voiceless consonants $(/ \mathrm{s} /, / \mathrm{t} /, / \mathrm{k} /)$, thereby creating a complementary rhyme as well as rhythm. The final line of the stanza (10) is a rhythmic blow to that which has gone before, and the scansion thus provides a moral judgement that is not directly specified in the language. It contains a linguistic repetition of the first line ("when I was"), but the change in position in the sentence and the final object ("young" in place of "Somalia") makes for a jarring contrast.

This passage displays the relational aspect to migrant constructions of "here" and "there"; rather than simply calling this nostalgia, we can see instead that what is lacking in one place is projected and imagined as located in the other. But it also shows how deeply intertwined notions of place are with notions of time (Boym, 2007). This is not a straightforward overlap: the weddings which borrowed or mimicked European conventions in the Somalia of Bilan's youth seemed pleasant enough at the time. Now, however, from the vantage point of middle-age and Europe, they seem staid and boring when compared with the rejuvenating Somali wedding: note how rhythmically disciplined Stanza 2 is in comparison to the more rhythmically exciting Stanza 3. Other interpretations are possible, and ethnopoetics is not necessary for analysis of (language) content and themes, but it enhances any such analysis considerably through making available the structure and form which is typically an integral part of the content and meaning. It becomes even more invaluable in this regard in analysis of long turns or indeed personal experience accounts, as demonstrated by Riessman (1990). 


\section{Dialogic, Performance, and Re-presentation}

Riessman (2008) observed that in much social research, quotations from participants are often presented "as if they dropped from the sky" (p. 62). She criticized the lack of demonstrable analysis of reflexivity involved in such representation, noting also that "the construction of meaning is not a private psychological process: it is socially accomplished" (1990, p. 117).

The role of the interviewer in the co-construction of the narrative can be written out of any representation, whether cleaned-up or ethnopoetic. In such representation, participants' voices are presented as transparently their own. However thorough the researcher has been with regard to reflexivity, however informative s/he has been in analyzing and proclaiming that reflexivity in the introduction, the role (and power) of the researcher as author is submerged and the "voices of narrative are ... treated as sources of authenticity, grounded in the biographical particularities of speaking subjects" (Atkinson, 2009, 2.11). The researcher-author is always speaking for the researched to a considerable degree (hooks, 1983; Spivak, 1988), since they hold the monopoly on the selection and interpretation of data. Removing the interviewer voice from the textual representation of the interview, however, masks this authorial monopoly (and the unequal power structures within it); it transforms a dialogue into a monologue, which is then attributed to the participant rather than the researcher-author. Ethnopoetics, we suggest, provides scope for the kind of "uncomfortable reflexivity" advocated by Pillow (2003, p. 188) and a means by which to demonstrate it to the reader. The example below comes from an interview with a participant Natasha met at a public event called "Inspiring Muslim Women." Amburo selected her office for the interview but then double-booked herself. We rearranged for the following week, this time at a café near her child's school. Half an hour before, she called to rearrange again.

The extract comes some 20 minutes into the interview, Amburo having already indicated that she was divorced. There is little evidence of the comfortable, conversational give-and-take as present in the extract with Bilan:

$\begin{array}{llll} & \text { Ok, } & & 1 \\ \text { Natasha: } & \text { and um, } & 2 \\ & \text { you didn’t get married again } \uparrow & 3 \\ \text { Amburo: } & \text { (1) } \quad \text { [Or you did } \uparrow & 4 \\ \text { Natasha: } & & 5\end{array}$


Amburo:

$\begin{array}{llr} & \text { Not, not. } & 7 \\ & \text { No I did get married } & \\ & \text { with /tt/ heh, } & 8 \\ & & 9 \\ & \text { Because this thing with Somalians } & 10 \\ & \text { you are Muslim } & 11 \\ & \text { so you cannot have boyfriend, } \quad \text { Yeah, yeah. } & 12 \\ \text { Natasha: } & & 13 \\ \text { Amburo: } & \text { that kind of thing, } \quad \text { So I was married } \quad \text { Ofter that, you know, ok. } & 14 \\ & \text { for a short time period, } & 16 \\ & & 17 \\ \text { Natasha: } & & 18\end{array}$

$\begin{array}{llr} & \text { Not, not. } & 7 \\ & \text { No I did get married } & \\ & \text { with /tt/ heh, } & 8 \\ & & 9 \\ & \text { Because this thing with Somalians } & 10 \\ & \text { you are Muslim } & 11 \\ & \text { so you cannot have boyfriend, } \quad \text { Yeah, yeah. } & 12 \\ \text { Natasha: } & & 13 \\ \text { Amburo: } & \text { that kind of thing, } \quad \text { So I was married } \quad \text { Ofter that, you know, ok. } & 14 \\ & \text { for a short time period, } & 16 \\ & & 17 \\ \text { Natasha: } & & 18\end{array}$

$\begin{array}{llr} & \text { Not, not. } & 7 \\ & \text { No I did get married } & \\ & \text { with /tt/ heh, } & 8 \\ & & 9 \\ & \text { Because this thing with Somalians } & 10 \\ & \text { you are Muslim } & 11 \\ & \text { so you cannot have boyfriend, } \quad \text { Yeah, yeah. } & 12 \\ \text { Natasha: } & & 13 \\ \text { Amburo: } & \text { that kind of thing, } \quad \text { So I was married } \quad \text { Ofter that, you know, ok. } & 14 \\ & \text { for a short time period, } & 16 \\ & & 17 \\ \text { Natasha: } & & 18\end{array}$

[No, no I didn't.

6

It can be seen that the opening question was not in any way neutral. It starts with a hedge (2) and finishes with a rising tone, but it is a negative question. The question could simply be dismissed as an example of bad interviewing: unlike with Bilan, the question fails to elicit a narrative or story at all, and goes against the recommended practice to use open Wh- questions (e.g., Fielding \& Thomas, 2008). But rather than dismiss this as bad practice, or ignore it entirely, this is a moment which invites reflexive scrutiny - why have I (Natasha) asked this question in this way? Am I presuming that Muslim women only marry once? Does it indicate a subconscious belief that it is morally dubious for a woman to divorce twice? Or is it perhaps that I am still worrying about my own hastily reorganized childcare arrangements and made uneasy by this inspiring Muslim woman?

And how is the question received? Amburo does not immediately take her turn, a delay which Natasha takes as a dispreferred response, which brings about a self-repair to the judgemental question (5), but in the meantime, Amburo has begun a response. The question is not just negative - it is also a statement which expects and invites confirmation (i.e., "No, I didn't get married again"). Such a way of asking the question has the potential to close down the subject. If it had not been for that selfrepair, would Amburo have simply failed to mention this second marriage? What implications, then, for the authorial knowledge claim about marriage?

Amburo is confused by the implied judgement. She begins by confirming the negative (6) but then reveals that in fact she did get married again. The tut (" $/ \mathrm{tt} /$ ") is a common Somali way to indicate disapproval, and her response verges on patronizing. She shifts the content of the conversation down to a very basic level (10-12) to explain 
to the non-Muslim, apparently prejudiced student the basic tenets of Muslim marriage. Natasha responds with a strong affirmative (13), indicating that she knows what Amburo is telling her. Amburo clearly picks up on this as she finishes with "that kind of thing." which is to say, "you don't need me to explain."

Even from this brief passage, it can be seen not just that knowledge is co-produced, but how that knowledge is co-produced. Power is apprehended in these moments not as a fixed one-way hierarchical dynamic between interviewer and interviewee, but as a fluid and contested process. Amburo and Natasha do not know each other, and it takes time for their conversation to flow. In the two stanzas that follow on, they make a conscious effort to come together, laughing and repeating each other's lines: the confusion has been replaced with symmetry and rhythm.

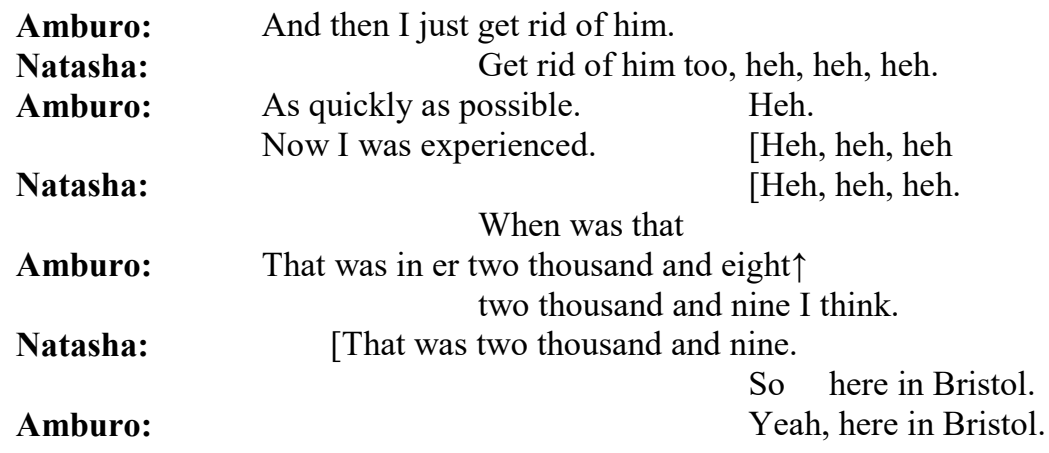

Repetition in conversation serves many functions, but one of its effects is to send a "metamessage of involvement" (Tannen, 2007, p. 61). It bonds the speakers both to the shared discourse and to each other. It demonstrates not just active listening, but connection and acceptance. Adding poetic line to the above passage reveals the repetition in a way that prose cannot. In addition, the lines reveal that this repetition is produced rhythmically and thus the poetic dimension of the conversation can be both observed and analyzed. Natasha and Amburo reach a moment when they appear to be singing from the same hymn sheet.

\section{Discussion}

In this regard, we discern even greater potential for ethnopoetics than that exemplified by Riessman. While Hymes considered ethnopoetics to be a better (possibly even truer), more finessed and more 
sympathetic means of capturing data from oral storytelling, Riessman is adamant that transcription, of whatever form, still involves interpretation. Therefore, the researcher-author is fully implicated in voicing his/her participants. Ethnopoetic transcription, like the detailed transcription of Conversation Analysis, can be seen as more problematic in this regard, since it appears to be a more authentic re-presentation of the participant's spoken words (see Bucholtz, 2000). But it also provides potential to make this interpretation explicit through spatial reorganization of the words. It is a matter of interpretation to decide line and stanza, just as it is a matter of interpretation to correct grammar or delete repetitions. Ethnopoetic analysis allows for this interpretation to be demonstrated visually: in the first extract this is achieved through marking the beginning of each stanza through hanging indentation; in the third extract by grouping the repetitions together. Riessman (1993) spoke of the researcher-author as an "artist" for whom the form of representation reflects their "views and conceptions - values about what's important" (p. 13). She compared the art of transcription to that of photography: "fix[ing] the essence of a figure." Ethnopoetics, we suggest, can be used to demonstrate this, and thus aid in the challenge of making the hand of the author explicit without compromising the voice of the participant or the readability of the text. The act of transcription (of any form) is not just an interpretation but a speech act in and of itself (Mazzei \& Jackson, 2012). The difficulty for the reflexive researcher is how to make this artistic endeavour visible to the reader throughout the body of the text. Borrowing from the idea of concrete poetry - in which the spatial organization or form of the poem mirrors the meaning and thus draws attention to its own artifice and artistry in a way that complements rather than compromises the meaning and content of the poem - ethnopoetics can helpfully draw attention to the engineering behind interpretation and representation. With (ethno)poetic licence, then, here is another participant, Hafsa, talking about marital separation in Bristol (an extract from the longer discussion in Carver (2021):

\section{Seventy-three Women}

Hafsa:

$\begin{array}{cc}\text { >I noticed a lot of places in here, } & 1 \\ \text { my husband tell me about it }< & 2 \\ \text { (.) -hhh is that (.) } & 3 \\ \text { seventy-three womans for this area, } & 4 \\ \text { for example, } & 5 \\ \text { seventy-three (.) } & 6 \\ \text { womans is } \uparrow \text { single! } & 7\end{array}$


Natasha:

$\mathrm{hmm} \uparrow \quad 8$

Hafsa:

$\begin{array}{cc}\text { hmm } \uparrow & 8 \\ \text { Oh my } \uparrow \text { word! } & 9 \\ \text { They kick out husband (1) } & 10 \\ \text { Hah! Seventy-three (.) } & 11 \\ \text { Ooooh! } & 12\end{array}$

\section{References}

Atkinson, P. (2009). Illness narratives revisited: The failure of narrative reductionism, Sociological Research Online 14(5)16.

Atkinson, P., \& Silverman, D. (1997). Kundera's Immortality: The interview society and the invention of the self. Qualitative Inquiry, 3, 304-325.

Blommaert, J. (2006a). Applied ethnopoetics, Narrative Inquiry, 16(1), 181-190.

Blommaert, J. (2006b) Ethnopoetics as functional reconstruction. Functions of Language, 13(2), 229-249.

Blackledge, A., Creese, A., \& Hu, R. (2016). Journal of Sociolinguistics, 20(5), 654676.

Boym, S. (2007). Nostalgia and its discontents. Hedgehog Review, 9(2), 7-18.

Bucholtz, M. (2000). The politics of transcription. Journal of Pragmatics, 32, 14391465.

Carver, N. (2021). Marriage, gender and refugee migration: Spousal relationships among Somali Muslims in the UK. Rutgers University Press.

Fielding, N., \& Thomas, H. (2008). Qualitative interviewing. In N. Gilbert (Ed.), Researching Social Life ( $3^{\text {rd }}$ Ed.) (pp. 123-144). Sage.

Gee, J. (2014). An introduction to discourse analysis: Theory and method (4 ${ }^{\text {th }}$ Ed.), Routledge.

Gee, J. (2015). Social linguistics and literacies $\left(5^{\text {th }}\right.$ Ed.), Routledge.

Heritage, J., \& Clayman, S. (2010). Talk in action: Interactions, identities, and institutions. Wiley-Blackwell.

Hymes, D. (1996). Ethnography, linguistics, narrative inequality: Towards an understanding of voice. Taylor and Francis.

hooks, b. (1982). Ain't I a woman: Black women and feminism. Pluto Press.

Labov, W. (2013). The language of life and death: The transformation of experience in oral narrative.: Cambridge University Press.

Mazzei, L., \& Jackson, A. (2012). Complicating voice in a refusal to "let participants speak for themselves." Qualitative Inquiry, 18(9), 745-751.

Mills, M., Moore, L., Chang, R., Kim, S. and Frick, B. (2021). Perceptions of Black Children's Narrative Language: A mixed-methods study. LSHSS 52(1), 84-99.

Pillow, W. (2003). Confession, catharsis, or cure? Rethinking the uses of reflexivity as methodological power in qualitative research. International Journal of Qualitative Studies in Education, 16(2), 175-196.

Plummer, K. (1995). Telling sexual stories: Power, change and social worlds. Routledge.

Riessman, C. (1990) Divorce talk: Women and men make sense of personal relationships. Rutgers University Press.

Riessman, C. (1993). Narrative analysis. Sage.

Riessman, C. (2008). Narrative methods for the human sciences. Sage. 
Spivak, G. C. (1988). Can the subaltern speak? In C. Nelson \& L. Grossberg (Eds.), Marxism and the interpretation of culture (pp. 271-313). University of Illinois Press.

Tannen, D. (2007). Talking voices: Repetition, dialogue and imagery in conversational discourse. Cambridge University Press.

Paul Atkinson, DSc, is Emeritus Professor of Sociology at Cardiff University. Recent publications include For Ethnography (2014), Thinking Ethnographically (2017), and Writing Ethnographically (2020). The fourth book in his SAGE quartet will be Crafting Ethnography. The fourth edition of Hammersley and Atkinson, Ethnography: Principles in Practice, was published in 2019. He is a Fellow of the Academy of Social Sciences and of the Learned Society of Wales. He and Sara Delamont were the founding editors of Qualitative Research.

Natasha Carver, $\mathrm{PhD}$, is Lecturer in International Criminology at the University of Bristol. Her research focuses on legal constructions of racialized and gendered identities. Her forthcoming book, Marriage, Gender and Refugee Migration (2021) uses ethnopoetic and narrative analysis to explore spousal relationships among UK-Somali migrants. 